\title{
Building Metal Organic Frameworks with Pyridine Fuctionalised Imidazolium Salts Spacers
}

\author{
Ibrahim T. Siraj and Mark D. Spicer
}

\begin{abstract}
Pyridine functionalised imidazolium salt (1, 3bis(4-picoly)imidazolium chloride) (1) was synthesized from the reaction of picolyl chloride and imidazole in the presence of sodium hydride in DMF through solvothermal process. It was characterized spectroscopically and by single crystal X-ray analysis. Reaction of this pyridine substituted imidazolium salt with Ag2O and $\mathrm{Cu2O}$ results in the formation of two coordination polymers, [Ag-((4-Picolyl)2 Imidazolium)2] hexafluorophosphate (4) and [Cu-((4-Picolyl)2 Imidazolium)2] hexafluorophosphate (5). These compounds were characterized spectroscopically (1H and 13C NMR), by elemental analysis and also using single crystal $\mathrm{X}$-ray diffraction. Compounds 4 and 5 crystallised in the monoclinic system, space group $P$ 2/c. and were found to be isostructural exhibiting 1D coordination frameworks.
\end{abstract}

Index Terms-Imidazolium salts, metal organic frameworks, pyridine, solvothermal.

\section{INTRODUCTION}

Metal organic frameworks (MOFs) are ordered porous coordination polymers containing organic linkers (ligands) connected by metal ions or their clusters. They have been receiving tremendous amount of interest in recent years due to their fine porous architecture which makes them to have potential applications in many areas including gas storage [1], gas separation [2], gas purication [3], catalysis [4] and drug delivery [5]. Huge amount of research have been reported [6] on the synthesis and applications of MOFs, most of which utilises neutral organic molecules containing $\mathrm{N}$ and $\mathrm{O}$ donors, most probably due to their strong donating tendencies which results in a more stable polymers.

One of the major features of MOFs are their chemically tunable abilities. Therefore MOF frameworks topologies can be designed by using specific types of starting organic linkers and metal connectors. In many cases organic ligands with pre-determined features suitable for specific frameworks have been prepared, and more recently their synthesis and their corresponding MOFs have been reviewed [7]. However most of these ligands were also neutral. Designing a ligand that will allow introduction of functional part into the open framework structures may open a new chapter in the design of new material. One of such example is the design of imidazolium salts and their use as a building block for cationic polymers. The imidazolium salts

Manuscript received April 10, 2013; revised June 3, 2013.

I. T. Siraj is with the Department of Pure and Industrial Chemistry, Bayero University, Kano. P.M.B. 3011, Kano, Nigeria (e-mail: istajdundun@yahoo.com).

M. D. Spicer is with the Department of Pure and Applied Chemistry, University of Strathclyde, Glasgow. 295 Cathedral Street, Glasgow G1 1XL, United Kingdom (e-mail: m.d.spicer@strath.ac.uk). when assemble into MOFs will allow the formation of Nheterocyclic carbene (NHC) complex within the pores of the MOFs frameworks, which will results in the construction of a very exciting material with huge potentials in catalysis and gas storage. The use of imidazolium salts as precursor for NHC complexes has been a well established area of chemistry [8].

Although such an approach seems highly promising, it has only attracted the attention of few research groups around the world, and only a handful of reports on the use of imidazolium salts as building blocks for MOFs have been forthcoming, most probably due to their cationic nature which may reduces the strength of their donating groups.

We became interested in the development of this imidazolium salts functionalised with non-chelating coordinating groups (e.g. nitrile, carboxylate, pyridine), and also investigate their assembly into MOFs. Either pre- or post-synthetic modification will then allow conversion of the imidazolium salt to a metal NHC complex. Hence, mono- or bimetallic functional MOFs can be envisaged.

\section{RESULTS AND DisCUSSIONS}

\section{A. Synthesis and Characterization of the Ligand}

The 1, 3-bis(4-picolyl)imidazolium salt (1), was prepared using solvo-thermal synthetic procedures. Two equivalent of 4-picolyl chloride, imidazole and sodium hydride $(60 \%)$ were dissolved in DMF and heated at $110^{\circ} \mathrm{C}$ in a sealed 20 $\mathrm{mL}$ pressure tube for $48 \mathrm{hrs}$. The dark brown oil produced was triturated with diethyl ether which gave a brown powder of the imidazolium salt. The chloride counter-anion was exchanged for hexafluorophosphate by dropwise addition of saturated solution of ammonium hexafluorophosphate to a solution of the imidazolium salt in water. Anion exchange was performed to improve the solubility giving more room for solvent selection. The formation of the products 1 and 2 were confirmed spectroscopically and in addition 1 by single crystal X-ray analysis.

${ }^{1} \mathrm{H}$ NMR, as expected, showed five peaks representing the five different hydrogen environments. The methylene spacer between the imidazole and the pyridine was observed at $5.63 \mathrm{ppm}$, a marked shift from the picolyl chloride starting material. There is also a significant shift of the -NCHNproton, as expected to $9.44 \mathrm{ppm}$, which is an indication of the formation of the target imidazolium salt (1). This was further supported by the expected six peaks in the ${ }^{13} \mathrm{C}$ NMR spectra. Ion in the mass spectrum $(\mathrm{M}+)$ at $\mathrm{m} / \mathrm{z}=251$ further confirm the synthesis of 1 . Both NMR $\left({ }^{1} \mathrm{H}\right.$ and $\left.{ }^{13} \mathrm{C}\right)$ and mass spectrometry suggest that the product has been purified but poor agreement between expected and observed values in microanalysis of the imidazolium chloride salt 
suggested otherwise. However the exchanged hexafluorophosphate salt, 2, was much purer and gave a good agreement between expected and observed values, thus confirming the synthesis of the imidazolium salt.

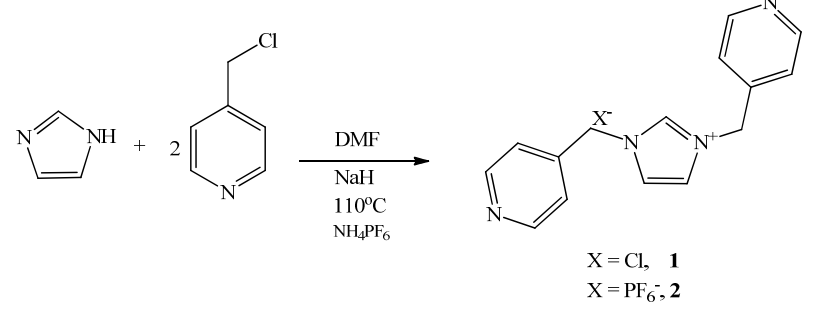

Scheme 1: Solvothermal synthesis of 1, 3-bis(4-picolyl)imidazolium salts

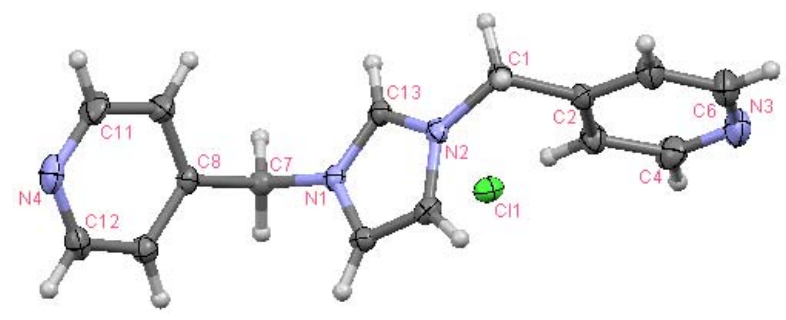

Fig. 1. Crystal structure of 1 , with thermal ellipsoids drawn at $50 \%$ probability level. Some selected bond length $(\AA)$ and bond angles $\left({ }^{\circ}\right)$. N $(1)$ $-\mathrm{C}(7)=1.472(2), \mathrm{N}(2)-\mathrm{C}(1)=1.461(2), \mathrm{N}(3)-\mathrm{C}(4)=1.336(2, \mathrm{~N}(3)-$ $\mathrm{C}(6)=1.335(2), \mathrm{C}(4)-\mathrm{N}(3)-\mathrm{C}(6)=116.77(15), \mathrm{C}(11)-\mathrm{N}(4)-\mathrm{C}(12)=$ $115.92(15), \mathrm{N}(2)-\mathrm{C}(1)-\mathrm{C}(2)=112.42(14), \mathrm{N}(1)-\mathrm{C}(7)-\mathrm{C}(8)=$ 109.26(13).

Single crystals suitable for X-ray diffraction were obtained by slow diffusion of diethyl ether into concentrated acetonitrile solutions of 1 . It crystallises in monoclinic space group $\mathrm{P} 22_{1} / \mathrm{c}$, and the crystallographic information is presented in Table 1. The asymmetric unit consists of one cationic imidazolium salt and one chloride counter ion (Fig. 1). The pyridyl group attached to the imidazole has identical bond angle $\left(\mathrm{C}(1)-\mathrm{N}(2)-\mathrm{C}(13) 126.0(1)^{\circ}\right.$ and $\mathrm{C}(13)-\mathrm{N}(1)$ $\left.-\mathrm{C}(7) 126.0(1)^{\circ}\right)$, which are all twisted assuming non planar conformation with respect to the attached imidazole ring.

\section{B. Synthesis and Structure of 1, 3-bis (4-Picolyl) Imidazolium Cationic Polymers}

In an attempt to convert the bis 4-picolyl imidazolium salt into $\mathrm{NHC}$ complexes of $\mathrm{Ag}(\mathrm{I})$ and $\mathrm{Cu}(\mathrm{I})$, the imidazolium salt (1) was reacted with $\mathrm{Ag}_{2} \mathrm{O}$ and $\mathrm{Cu}_{2} \mathrm{O}$ respectively according to scheme 2 . These gave a colourless products each and surprisingly the ${ }^{1} \mathrm{H}$ NMR spectrum of the product in both $\mathrm{Ag}(\mathrm{I})$ and $\mathrm{Cu}(\mathrm{I})$ targeted carbene shows that the downfield -NCHN- signal did not disappear, but only slightly shifted from $9.44 \mathrm{ppm}$ in the ligand to ca $9.40 \mathrm{ppm}$ in the product. N-heterocylclic carbene are normally associated with disappearance of the most acidic proton (-NCHN-) of the azolium ring. This lack of disappearance of the -NCHN- clearly shows the deprotonation of the most acidic -NCHN- proton fails, and also other imidazole protons signals are intact in the spectrum at $7.89 \mathrm{ppm}$ therefore ruling out any possibility of abnormal proton abstraction from the imidazolium salts as such no chances of abnormal carbene formation as was observed in some system [9]. Therefore ${ }^{1} \mathrm{H}$ NMR analysis rules out any possibility of in situ carbene formation, which explain why no traces of silver bis(4-picolyl) carbene complexes were found. But interestingly a careful analysis of the ${ }^{1} \mathrm{H}$ NMR suggests that the metal ion preferentially binds to the pyridine nitrogen forming the imidazolium salts polymers 4 and 5 respectively instead of the N-heterocyclic carbene complex (3). This is not surprising because silver(I) has shown a preference to coordinate to amine [10] but what is surprising is the inability of the imidazolium salts to be deprotonated despite using excess of $\mathrm{M}_{2} \mathrm{O}(\mathrm{M}=\mathrm{Ag}$ or $\mathrm{Cu})$.

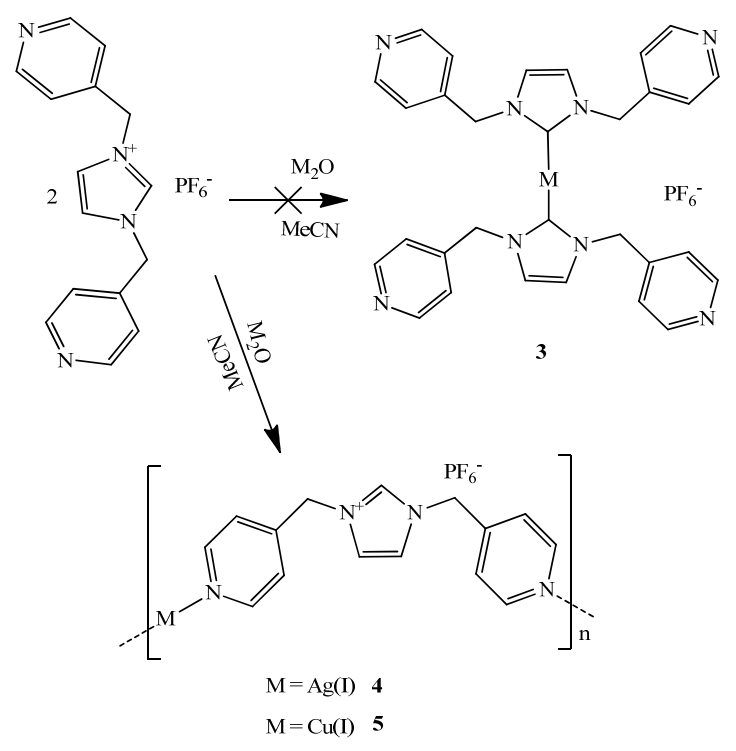

Scheme 2: Synthesis of imidazolium salt based cationic polymers

The formation of the polymer can be explained by the shift in the signal attributed to the pyridine protons in ${ }^{1} \mathrm{H}$ NMR spectrum, those of imidazole are almost identical to the starting ligand. The ${ }^{1} \mathrm{H}$ NMR spectra of 4 and 5 are similar and the aromatic $-\mathrm{C}=\mathrm{N}$ - stretching vibration at ca $1640 \mathrm{~cm}^{-1}$ in the IR had shifted to ca $1617 \mathrm{~cm}^{-1}$. Good agreement in elemental analysis of both 4 and 5 further confirmed the formation of these polymers. In addition they were confirmed by X-ray crystallographic analysis when single crystal suitable for X-ray diffraction were obtained by slow diffusion of diethyl ether into acetonitrile solutions of the compounds (4 and 5). The diffraction results shows the two polymers are isostructural, and therefore $\mathrm{Ag}(\mathrm{I})$ complex (4) will be discussed in more detailed as representative of both.

4 crystallises in monoclinic space group $\mathrm{P} 2 / \mathrm{c}$, the crystallographic information are given in Table 1, the asymmetric unit contains one $\operatorname{Ag}(\mathrm{I})$ ion, one ligand (2) and one and half hexafluorophosphate anion. The $\operatorname{Ag}(\mathrm{I})$ ion coordinates to four imidazolium salt cationic ligands via the pyridine groups giving an approximately tetrahedral coordination geometry (Fig. 2). Three of the four pyridyl rings are twisted around the $\mathrm{Ag}(\mathrm{I})$ centre assuming nonplanar conformation with $\mathrm{N}(1)-\mathrm{Ag}(1)-\mathrm{N}(1)-\mathrm{C}(7)$ torsion angle of $117.35^{\circ}$. The $\operatorname{Ag}(1)-\mathrm{N}(1)$ and $\operatorname{Ag}(1)-\mathrm{N}(2)$ bond length are 2.314(7) $\AA$ and 2.285(5) $\AA$ respectively and are within the range of $\mathrm{Ag}-\mathrm{N}$ bond length of similar compounds reported [11]. The $\mathrm{N}-\mathrm{Ag}-\mathrm{N}$ angles are in the range of $108.3(2)^{\circ}-111.0(2)^{\circ}$ which are also within the 
range of reported similar pyridine polymers [12]. The $\mathrm{N}(1)$ - C(7) and $\mathrm{N}(1)-\mathrm{C}(8)$ bond length are 1.341(1) $\AA$ and 1.352(1) $\AA$ respectively. These values were observed to be slightly higher than the corresponding distances in the ligand (1), which has an average bond length of $1.3337 \AA$.
This may be due to the impact of the nitrogen coordination which increases the distance to its neighboring carbon atom in the pyridine ring.

\begin{tabular}{|c|c|c|c|}
\hline Compound & 1 & 4 & 5 \\
\hline Chemical Formula & $\mathrm{C}_{15} \mathrm{H}_{15} \mathrm{~N}_{4} \mathrm{Cl}_{1}$ & $\mathrm{Ag}_{1} \mathrm{C}_{30} \mathrm{H}_{30} \mathrm{~N}_{8} \mathrm{P}_{2} \mathrm{~F}_{12}$ & $\mathrm{Cu}_{1} \mathrm{C}_{15} \mathrm{H}_{15} \mathrm{~N}_{4} \mathrm{P}_{1} \mathrm{~F}_{6}$ \\
\hline Formula weight & 286.8 & 898.4 & 461 \\
\hline Colour & Colourless & Colourless & Colourless \\
\hline Lattice Type & Monoclinic & Monoclinic & Monoclinic \\
\hline Spacegroup & P $2{ }_{1} / \mathrm{c}$ & $\mathrm{P} 2 / \mathrm{c}$ & $\mathrm{P} 2 / \mathrm{c}$ \\
\hline $\mathbf{a} / \mathbf{\AA}$ & $15.2689(5)$ & $13.0640(3)$ & $12.7435(3)$ \\
\hline b/ $\AA$ & $8.1714(2)$ & $6.3399(12)$ & $6.3113(17)$ \\
\hline c/ $\AA$ & $11.8084(5)$ & $24.0380(4)$ & $23.8491(7)$ \\
\hline$\alpha /{ }^{\circ}$ & 90 & 90 & 90 \\
\hline$\beta /{ }^{\circ}$ & $104.523(4)$ & $99.233(19)$ & $100.687(3)$ \\
\hline$\gamma /{ }^{\circ}$ & 90 & 90 & 90 \\
\hline $\mathbf{V} / \AA$ & $1426.24(8)$ & 1965.1(4) & $1884.87(4)$ \\
\hline $\mathbf{Z}$ & 4 & 4 & 4 \\
\hline $\mathbf{T} / \mathbf{K}$ & $293(2)$ & 293(2) & 293(2) \\
\hline$\rho / g c m-3$ & 1.336 & 3.03 & 1.62 \\
\hline $\boldsymbol{\mu} / \mathbf{m m}^{-1}$ & 0.263 & 1.367 & 1.307 \\
\hline F000 & 600 & 1787.7 & 923.8 \\
\hline No of reflection collected & 8677 & 9125 & 11408 \\
\hline $\begin{array}{l}\text { No of independent } \\
\text { reflections/( }\left(\mathbf{R}_{\text {int }}\right)\end{array}$ & $3500 / 0.032$ & $4509 / 0.1145$ & $4651 / 0.0342$ \\
\hline $\begin{array}{l}\text { No of observed Reflection (I>2 } \\
\sigma(I))\end{array}$ & 2667 & 2208 & 3624 \\
\hline No of parameters Refined & 176 & 254 & 273 \\
\hline R1 (obsd/all) & $0.044 / 0.066$ & $0.085 / 0.181$ & $0.0508 / 0.0712$ \\
\hline wR2 (obsd/all) & $0.084 / 0.094$ & $0.162 / 0.216$ & $0.1121 / 0.1243$ \\
\hline $\begin{array}{l}\text { Largest difference in peak and } \\
\text { hole } \mathrm{e}^{-3}\end{array}$ & $0.263,-0.237$ & $0.794,-1.294$ & $0.855,-0.936$ \\
\hline
\end{tabular}

The structure further reveals that each $\mathrm{Ag}$ (I) is linking two imidazolium cationic ligand (2), with two $\mathrm{PF}_{6}^{-}$serving as counter ions (Fig. 2). They assembled together to form a an extended rings of the cationic ligand connected by the $\operatorname{Ag}(\mathrm{I})$ ion. Each charge of the cationic framework is balanced by $\mathrm{PF}_{6}^{-}$anions Some of the $\mathrm{PF}_{6}^{-}$are encapsulated within the ring and the others located at the side of the ring chain further stabilising the polymer as shown in Fig. 3 a and $b$. 


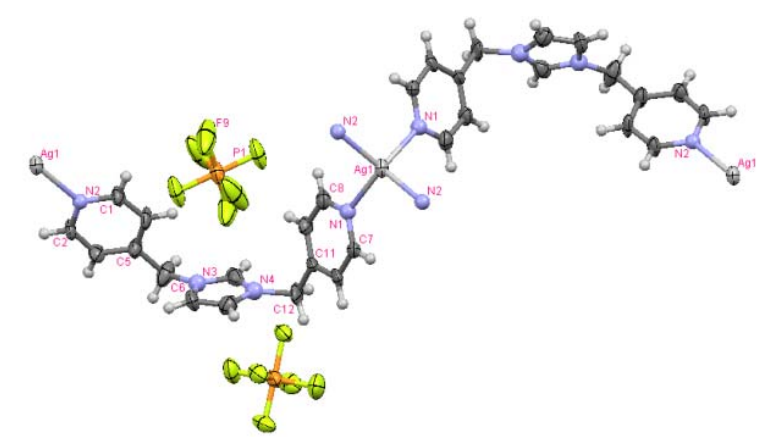

Fig. 2. Crystal structure of 4 including the asymmetric unit, thermal ellipsoids drawn at $50 \%$ probability level. Some selected bond length $(\AA)$ and bond angles $\left({ }^{\circ}\right) . \operatorname{Ag}(1)-\mathrm{N}(1)=2.314(7), \operatorname{Ag}(1)-\mathrm{N}(2)=2.285(5), \mathrm{N}(1)$ $-\mathrm{C}(8)=1.35(1), \mathrm{N}(1)-\mathrm{C}(7) 1.34(1), \mathrm{N}(1)-\mathrm{Ag}(1)-\mathrm{N}(2) 108.3(2), \mathrm{N}(1)-$ $\operatorname{Ag}(1)-\mathrm{N}(1)=111.0(2), \mathrm{N}(2)-\operatorname{Ag}(1)-\mathrm{N}(2)=112.1(2), \mathrm{C}(7)-\mathrm{N}(1)-$ $\operatorname{Ag}(1)=121.8(5), C(8)-\mathrm{N}(1)-\operatorname{Ag}(1)=122.2(5)$

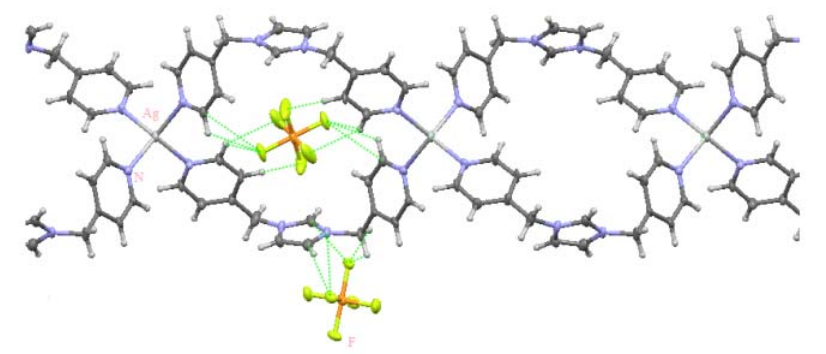

(a)

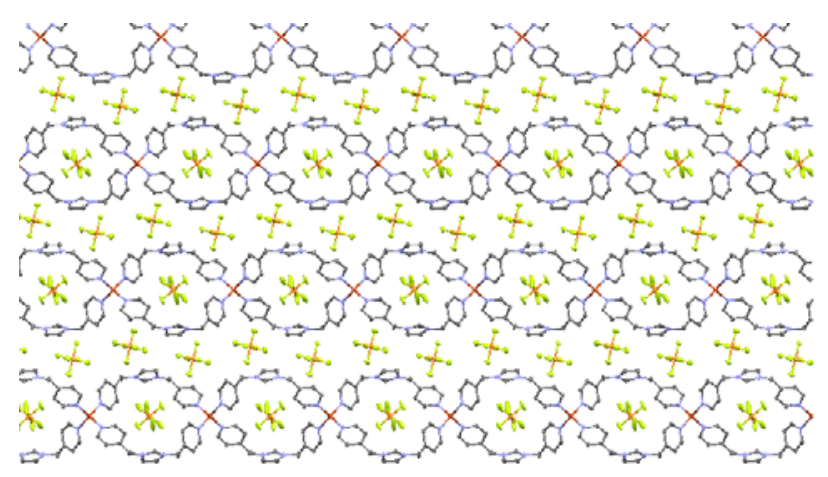

(b)

Fig. 3. The network in 4, (a) showing the interaction environment around $\mathrm{PF}_{6}^{-}$(b) Packing diagram viewed along crystallographic b axis, hydrogen atoms, hydrogen bonding omitted for clarity

The $\mathrm{PF}_{6}{ }^{-}$anion further support the crystal packing of the polymer 4 by interacting with three different layers of the compound, through $\mathrm{C}-\mathrm{H}---\mathrm{F}$ hydrogen with a separation in the range of $2.535 \AA-2.609 \AA$ (Fig. 4).

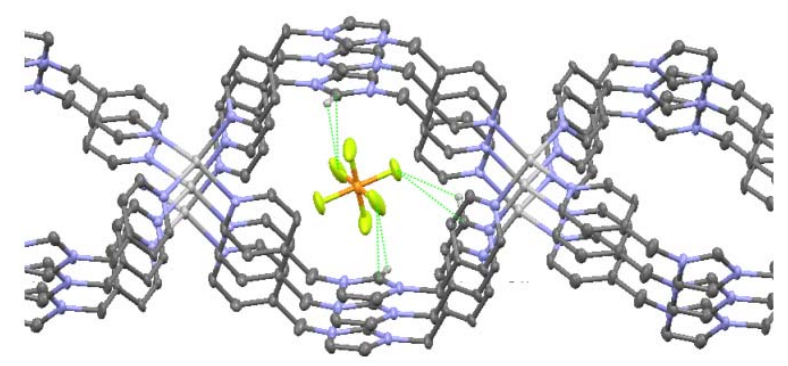

Fig. 4. Parallel stacking of the network in 4, hydrogen atoms, $\mathrm{PF}_{6}{ }^{-}$anion, hydrogen bonding omitted for clarity.

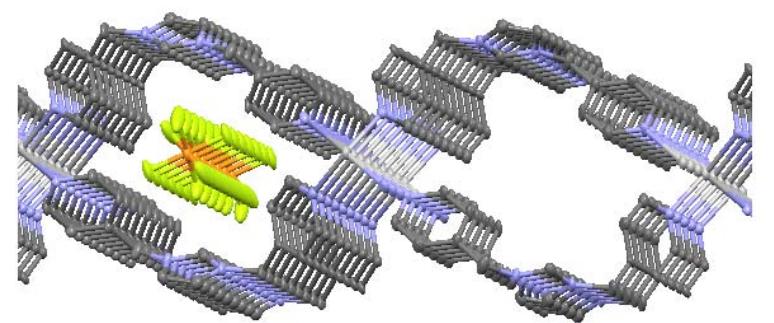

Fig. 5. Parallel stacking of the network in 4, hydrogen atoms, $\mathrm{PF}_{6}^{-}$anion, hydrogen bonding omitted for clarity, view along the channel.

Compound 5 is isostructural with 4 , with only small differences in them. Bonding distances in $\mathrm{Cu}(\mathrm{I})$ polymer are slightly less in line with the smaller size of its ionic radii compared to $\operatorname{Ag}(\mathrm{I})$ compound.

In conclusion, a new picolyl functionalised imidazolium salts has been synthesised and characterised. To the best of our knowledge this is the first report on the synthesis of bis (4-picolyl) imidazolium salt and has the potentials to be assembled into MOFs with larger pores as such given a high surface area with low density materials. It can also be use to as precursor to $\mathrm{N}$-heterocyclic carbene complexes, hence NHC based MOFs can be envisage. This imidazolium salt (1) has been used to produce two isotructural cationic polymers which were characterised spectroscopically (NMR and Mass spectrometry), by elemental analysis and also by single crystal X-ray analysis. The parallel stacking of the layers gave rise to $1 \mathrm{D}$ tubular channels carrying anionic $\mathrm{PF}_{6}{ }^{-}$arrays.

\section{EXPERIMENTAL SECTION}

\section{A. General Considerations.}

Unless otherwise stated all reactions were performed under nitrogen using standard Schlenk line techniques. All reagents were purchase from Aldrich and were used without further purification.

All infrared spectra (KBr disk, 400-4000 $\left.\mathrm{cm}^{-1}\right)$ were recorded on Nicolet Avatar 360 FTIR spectrometer. Mass spectra were recorded on a thermo Finnigan LCQDUO mass spectrometer using ESI. ${ }^{1} \mathrm{H}$ and ${ }^{13} \mathrm{C}$ NMR spectra were recorded on Bruker AVANCE/DPX 400(400 MHz) and or AVANCE/DRX 500 (500 MHz) in DMSO with tetramethyl silane as standard. Elemental analyses were carried out at the micro analytical laboratory at the University of Strathclyde, Glasgow UK.

Single crystal measurements were made at $123 \mathrm{~K}$ with graphite monochromated MoK $\alpha 1$ radiation (wavelength $0.71073 \AA$ ) on an Oxford Diffraction Gemini S diffractometer equipped with a CCD detector and a variable temperature device. Initial atomic sites were located using direct methods. Remaining non-hydrogen atom sites were calculated using difference Fourier maps. Refinement of atomic co-ordinates and thermal parameters was to convergence and by full-least squares methods on $\mathrm{F}^{2}$ within SHELX-97 [13]. All H-atoms were placed in calculated positions and in a riding mode. Reported wR2 values are based on $\mathrm{F}^{2}$ and all reflections, whilst reported $\mathrm{R} 1$ values are based on $\mathrm{F}$ and on observed reflections with $\mathrm{I}>2 \sigma(\mathrm{I})$. 


\section{B. Synthesis of Bis 1, 3-(4-Picolyl) Imidazolium Chloride}

A solution of 4- picolyl chloride hydrochloride $(2.00 \mathrm{~g}$, $12.00 \mathrm{mmol}$ ) was neutralized with a saturated solution of sodium hydroxide. The liberated 4-picolyl chloride was extracted into diethyl ether $(20 \times 3)$, separated and the ether layer dried using sodium sulphate and filtered. The filtrate was concentrated to $20 \mathrm{~mL}$ and $5 \mathrm{ml}$ DMF was added and the ether removed under reduced pressure. The solution was transferred to a $20 \mathrm{~mL}$ pressure tube and imidazole $(0.40 \mathrm{~g}$, $5.89 \mathrm{mmol})$ and sodium hydride $60 \%(0.24 \mathrm{~g}, 6.00 \mathrm{mmol})$ were added, the mixture was heated at $110^{\circ} \mathrm{C}$ for 48 hours. A dark brown oily product was obtained by addition of diethyl ether. It was recrystallised by diffusion of diethyl ether into a methanol solution. Yield $(0.97 \mathrm{~g}, 56 \%)$. ${ }^{1} \mathrm{H}$ NMR (DMSO-d6) $\delta$ ppm: 9.44 (s -NCHN- of imid., 1H), 8.74 (d, $\mathrm{CH}-$ of Py 4H ), 7.91 (d, -CH- of imid., 2H), 7.55 (d, -CHof Py, $4 \mathrm{H}), 5.63\left(\mathrm{~s},-\mathrm{CH}_{2^{-}}\right.$of imid,. $\left.4 \mathrm{H}\right) .{ }^{13} \mathrm{C}\left\{{ }^{1} \mathrm{H}\right\} \mathrm{NMR}$ (DMSO-d6) $\delta$ ppm: $147.98\left(\mathrm{C}_{\mathrm{Py}}\right), 146.44\left(\mathrm{C}_{\mathrm{Py}}\right), 137.88$ $\left(\mathrm{C}_{\text {imid }}\right) 123.47\left(\mathrm{C}_{\text {imid }}\right), 123.41\left(\mathrm{C}_{\mathrm{Py}}\right), 50.41\left(\mathrm{C}\right.$ of $\left.-\mathrm{CH}_{2^{-}}\right) \mathrm{MS}$ (ESI, methanol; m/z): $251[\mathrm{M}]^{+}$.

\section{Synthesis of Bis 1, 3-(4-Picolyl) Imidazolium Hexafluorophosphate}

$1(1.00 \mathrm{~g}, 3.50 \mathrm{mmol})$ was dissolved in the minimum amount water and a saturated solution of $\mathrm{NH}_{4} \mathrm{PF}_{6}$ was added to give a brownish precipitate. The mixture was stirred for 2 hours, filtered, washed with diethyl ether and dried under vacuum. Yield 1.30g (93.80\%) Anal. Calculated for $\mathrm{C}_{15} \mathrm{H}_{15} \mathrm{~N}_{4} \mathrm{Cl}_{1} .1 \frac{1}{2}\left(\mathrm{PF}_{6}\right): \mathrm{C}, 38.41 ; \mathrm{H}, 3.23 ; \mathrm{N}, 11.95$. Found: C, 38.32; H, 3.43; N, 11.04 .

\section{Synthesis of [Ag-((4-Picolyl) 2 Imidazolium) 2] Hexafluorophosphate}

2 (1g, $2.26 \mathrm{mmol})$ was dissolved in $20 \mathrm{~mL}$ acetonitrile, $\mathrm{Ag}_{2} \mathrm{O}(0.52 \mathrm{~g}, 2.26 \mathrm{mmol})$ was added and the mixture refluxed overnight. It was filtered through celite to remove unreacted silver oxide. The solvent was removed under vacuum to yield a white precipitate which was recrystallised from acetonitrile - diethyl ether by vapour diffusion. Yield $0.28 \mathrm{~g}(62.22 \%)$. ${ }^{1} \mathrm{H}$ NMR (DMSO-d $\left.{ }_{6}\right) \delta$ ppm: 9.40 (s NCHN- of imid., 1H), 8.65 (d, -CH- of Py 4H), 7.89 (d, $\mathrm{CH}-$ of imid., 2H), 7.35 (d, -CH- of Py, 4H), 5.53 (s, - $\mathrm{CH}_{2-}$ of imid,. 4H). MS (ESI, methanol; m/z): $251[\mathrm{M}]^{+}$.

\section{E. Synthesis of [Cu-((4-Picolyl) 2 imidazolium) 2] Hexafluorophosphate}

2 (1g, $2.26 \mathrm{mmol})$ was dissolved in $20 \mathrm{~mL}$ acetonitrile, $\mathrm{Cu}_{2} \mathrm{O}(0.28 \mathrm{~g}, 2.26 \mathrm{mmol})$ was added and the mixture refluxed overnight. It was filtered through celite to remove unreacted copper (I) oxide. The solvent was removed in vacuum which gave a light green precipitate which was recrystallised from acetonitrile - diethyl ether by vapour diffusion. Yield 0.31g, (68.89\%) ${ }^{1} \mathrm{H}$ NMR (DMSO-d $\left.{ }^{6}\right) \delta$ ppm: 9.39 (s -NCHN- of imid., 1H), 9.20 (br, -CH- of Py 4H ), 7.89 (d, -CH- of imid., 2H), 7.49 (d, -CH- of Py, 4H), 5.49 (s, $-\mathrm{CH}_{2}$ - of imid,. 4H). MS (ESI, methanol; m/z): 251 $[\mathrm{M}]^{+}$. Anal. Calculated for $\mathrm{Cu}_{1} \mathrm{C}_{30} \mathrm{H}_{30} \mathrm{~N}_{8} \cdot 3 \mathrm{PF}_{6}$ : C, 35.97; $\mathrm{H}$, 3.02; N, 11.19. Found: C, 35.87; H, 2.86; N, 11.29.

\section{ACKNOWLEDGMENT}

Thanks to Alan Kennedy of Department of pure and applied chemistry, university of Strathclyde, Glasgow, For his help with the X-ray data. Ibrahim thanks Bayero university, Kano and Kano state government for funding.

\section{REFERENCES}

[1] M. P. Suh, H. J. Park, T. K. Prasad, and D.-W. Lim, "Hydrogen Storage in Metal-Organic Frameworks," Chemical Reviews, vol. 112, pp. 782-835, 2012.

[2] J.-R. Li, J. Sculley, and H.-C. Zhou, "Metal organic frameworks for separation," Chemical Reviews, vol. 112, pp. 869-932, 2012.

[3] D. Britt, D. Tranchemontagne, and O. M. Yaghi, Proceedings of the National Academy of Sciences, vol. 105, pp. 11623-11627, 2008.

[4] J. S. Seo, D. Whang, H. Lee, S. I. Jun, J. Oh, Y. J. Jeon, and K. Kim, "A homochiral metal-organic porous material for enantioselective separation and catalysis," Nature, vol. 404, pp. 982-986, 2000

[5] R. J. Kuppler, D. J. Timmons, Q.-R. Fang, J.-R. Li, T. A. Makal, M. D. Young, D. Yuan, D. Zhao, W. Zhuang, and H.-C. Zhou, "Potential applications of metal-organic frameworks," Coordination Chemistry Reviews, vol. 253, pp. 3042-3066, 2009.

[6] S. Kitagawa, R. Kitaura, and S.-I. Noro, Functional Porous Coordination Polymers, Angewandte Chemie International Edition, vol. 43, pp. 2334-2375, 2004

[7] F. A. A. Paz, J. Klinowski, S. M. F. Vilela, J. P. C. Tomé, J. A. S. Cavaleiro, and J. Rocha, "Ligand design for functional metal-organic frameworks," Chemical Society Reviews, vol. 41, pp. 1088, 2012.

[8] W. A. Herrmann and C. Köcher, "N-Heterocyclic Carbenes," Angewandte Chemie International Edition in English, vol. 36, no. 20, pp. 2162-2187, 1997.

[9] P. L. Arnold and S. Pearson, Coordination Chemistry Reviews, vol. 251, pp. 596-609, 2007

[10] O. Kuhl, Functionalised N-Heterocyclic Carbene Complexes, John Wiley \& Sons Ltd, West Sussex, 2010.

[11] L. C. Silva, R. Ahmad, M. J. Carr, A. Franken, J. D. Kennedy, and M. J. Hardie, Crystal Growth \& Design, vol. 7, pp. 658-667, 2007

[12] J.-J. Jiang, X.-P. Li, X.-L. Zhang, B.-S. Kang, and C.-Y. Su, “A new $\mathrm{Ag}$ (I)-4,4'-bipyridine coordination polymer of honeycomb $(6,3)$ networks containing a Ag6(4,4'-bipy) 6 hexagonal ring of $17 \times 26 \AA$ dimensions," CrystEng Comm, vol. 7, pp. 603, 2005

[13] G. M. Sheldrick, "SHELXS-97 Program for crsytal Structure Solution," University of Gottingen, Germany. 1998

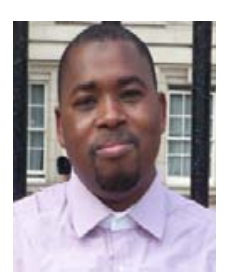

Ibrahim T. Siraj was born in Kano on $15^{\text {th }}$ July 1974. He obtained a PhD in chemistry from University, of Strathclyde, Glasgow United Kingdom in 2012, Msc inorganic chemistry in 2004 and B.Sc chemistry in 1998 both from Bayero University Kano Nigeria. He started working as a graduate assistant in 2000 in the department of pure and industrial chemistry, Bayero University, Kano Nigeria, and currently he is a lecturer 1 in the same department. His research interest centered towards synthesis of novel imidazolium salts and their conversion into N-heterocyclic carbenes and their complexes, more recently his interest also includes the uses of this imidazolium salts as building block in the constructions of metal organic frameworks. 